\title{
Work in Progress: Investigating the Role of Social Responsibility on Veteran Student Retention
}

\section{Dr. Stacey E. Tucker-Kulesza, Kansas State University}

Dr. Stacey Tucker-Kulesza is an assistant professor in the civil engineering department at Kansas State University. Dr. Tucker-Kulesza is a graduate of the American Society of Civil Engineers Excellence in Civil Engineering Education (ExCEED). She teaches undergraduate and graduate courses in geotechnical engineering.

\section{Dr. Grace J. Liang, Kansas State University}

Grace J. Liang is a faculty in the Department of Educational Leadership at Kansas State University (USA). Her research interests focus on school leadership, professional development and learning in STEM, equity for women and racial minorities, and leadership for community engagement. She holds a PhD from the University of Georgia in Educational Administration and Policy.

\section{Dr. Eric J. Fitzsimmons, Kansas State University}

Dr. Eric Fitzsimmons is an assistant professor in the civil engineering department at Kansas State University and licensed professional engineering in the State of Kansas. Dr. Fitzsimmons is a graduate of the American Society of Civil Engineers Excellence in Civil Engineering Education (ExCEED) program. HE teaches undergraduate and graduate courses in transportation engineering.

\section{Dr. Jeff Zacharakis, Kansas State University}

Jeff Zacharakis is a professor of adult learning and leadership in the Department of Educational Leadership. His areas of research include leader and organizational development. 


\section{Work in Progress: Investigating the role of social responsibility on veteran student retention}

Introduction

This study addresses national initiatives to increase and diversify the engineering workforce [1] [2]. According to the findings from the National Science Foundation (NSF) Workshop on Enhancing Post-9/11 Veteran Educational Benefits, the current veteran student population holds the greatest potential to increase representation of underrepresented groups in engineering [3]. Unfortunately, research has indicated that discontinued and dismissal rates of veteran students in engineering are significantly higher than traditional engineering student attrition nationally [4]. Although there is ample research on how to retain students in engineering programs, there is a lack of data-driven research that explores the retention of veteran students [4] [5]. The American Council on Education Report of Military Service Members and Veterans in Higher Education defined a veteran's military service as an identifiable difference from traditional engineering students who are under the age of 24 and fiscally dependent on their parents [6]. Therefore, a review of literature regarding general engineering student retention is unlikely to be instrumental for veteran students. The limited literature on veteran engineering student retention revealed significantly higher attrition rates (dismissal or discontinued enrollment) overall for this population and identified that the first year is the most critical period [4].

This research project seeks to investigate and determine if social responsibility is a fundamental motivator that encourages many to join the military, and can be linked to veteran student success when incorporated in the classroom starting with first-year engineering students. The term social responsibility refers to the ways engineering can positively impact society [7] and the responsibility of engineers to evaluate the broad impacts of their designs on society and the environment [8]. The principles of social responsibility are what attract many students to engineering, specifically students from historically underrepresented groups [9]. Pryor et al. [10] found that 72 percent of first-year college students specified "help[ing] others in difficulty" as an objective that was important to them, up 13.3 percent from 1987. Building on this, the National Academy of Engineering established that colleges should focus on the benefits that engineering has on society as a way to attract students [11]. On the other hand, the commitment to service has been one of the core ideals of all branches of military (e.g., the U.S. Air Force "service before self" ideal). There exists a common theme between the core ideals of the military community and why many students select engineering. Numerous researchers have investigated the role of social responsibility on retention of engineering students [12] [13] [14]. However, to date there is limited research on how connecting social responsibility from military service to social responsibility of engineering may improve retention of veterans in engineering programs.

\section{Methodology}

Canney and Bielefeldt [15] developed a model for assessing first-year engineering student understanding of social responsibility. The Professional Social Responsibility Development Model (PSRDM) was administered to students at five institutions using a mixed methods approach. Canney and Bielefeldt [16] utilized the PSRDM model as a theoretical basis to develop the Engineering Professional Responsibility Assessment (EPRA) survey. A modified 
EPRA survey was used in this study, aimed at measuring social responsibility in veteran and first-year students at Kansas State University. The current pilot survey for this research project contains three components: Likert-scale questions to measure dimensions of PSRDM, demographics, and previous job attributes (military occupational specialty code) for the veterans. The original EPRA survey [16] outlines the twelve steps described by the PSRDM, which are broken into three paths: social awareness, professional development, and combined social awareness and professional development. The EPRA survey contains 65, (primarily Likert-style) questions and demographics. The authors first reviewed the EPRA survey to identify if any questions could be removed to shorten the overall survey, because the additional questions asked of veterans increased the survey length. Lord et al. [17] developed a survey for their study of veteran students and ultimately shortened the length of the survey at the suggestion of their external advisory board. A subset of questions was removed from the first two paths of social awareness and professional development that were deemed similar to other questions in the survey. All questions within the combined social awareness and professional development path related to costs/benefits and realization were removed as these questions were again found elsewhere and thus were repetitive. Additionally, the cost/benefits questions and an additional question were drawn from the Pittsburgh Freshman Engineering Attitudes Survey [18], which was demonstrated to have problems with the scale design and was later revised [19]. These questions were removed from the modified survey in this study. Ultimately 24 questions were drawn from the EPRA tool (excluding demographics).

Two separate Listservs were prepared so the students were selected at random from their respective populations for piloting. Monetary incentives (different amounts for each group) were used to encourage participation, particularly participation from the veteran student group [20]. Three questions were added to the veteran population survey connecting military experiences and engineering; these Likert-scale questions are shown in Table 1. The demographics questions for all participants include: age, gender identity, marital status, race/ethnicity, parent/guardian highest education levels, if they have family members who are/were engineers, and if they have previous work experience or technical training in an engineering related field. Students who self-identified as veterans in the college of engineering were asked an additional set of questions regarding their military background (see Table 1).

An external advisory board was created to review the survey instrument prior to piloting. The external advisory board is comprised of seven veterans at the university, including university administrators, engineering faculty, a graduate student, and an undergraduate student. The advisory board covers a range of demographics, military ranks (enlisted to former chairman of the Joint Chiefs of Staff), and academic and professional connections with engineering. The advisory board reviewed the initial pilot survey individually and then met as a group for further discussions to ensure the questions were phrased in a meaningful way. Suggestions included clarifying terminology such as service (i.e. service to a community or military service), clarifying when college credit was received (before/during service), where/how college credit was obtained, and limiting the overall survey length. The pilot survey was modified based on the input from the advisory board and submitted to Internal Review Board (IRB) for approval to proceed. 
Table 1: Additional questions for veteran students

\begin{tabular}{|c|c|c|}
\hline Type of question & \multicolumn{2}{|l|}{ Question } \\
\hline \multirow{3}{*}{$\begin{array}{l}\text { Relating military } \\
\text { to engineering }\end{array}$} & \multicolumn{2}{|c|}{$\begin{array}{l}\text { I cannot see the connection between my serve in the military and the profession of } \\
\text { engineering. }\end{array}$} \\
\hline & \multicolumn{2}{|c|}{$\begin{array}{l}\text { The profession of engineering provides a pathway for continuing my wanting to } \\
\text { serve, be it communities locally, nationally, and globally. }\end{array}$} \\
\hline & \multicolumn{2}{|c|}{$\begin{array}{l}\text { I am pursuing a degree in engineering because it is a profession similar to what I have } \\
\text { done in the military - it is action-based and brings real changes in human lives. }\end{array}$} \\
\hline \multirow[t]{6}{*}{$\begin{array}{l}\text { Military } \\
\text { background }\end{array}$} & \multicolumn{2}{|c|}{ 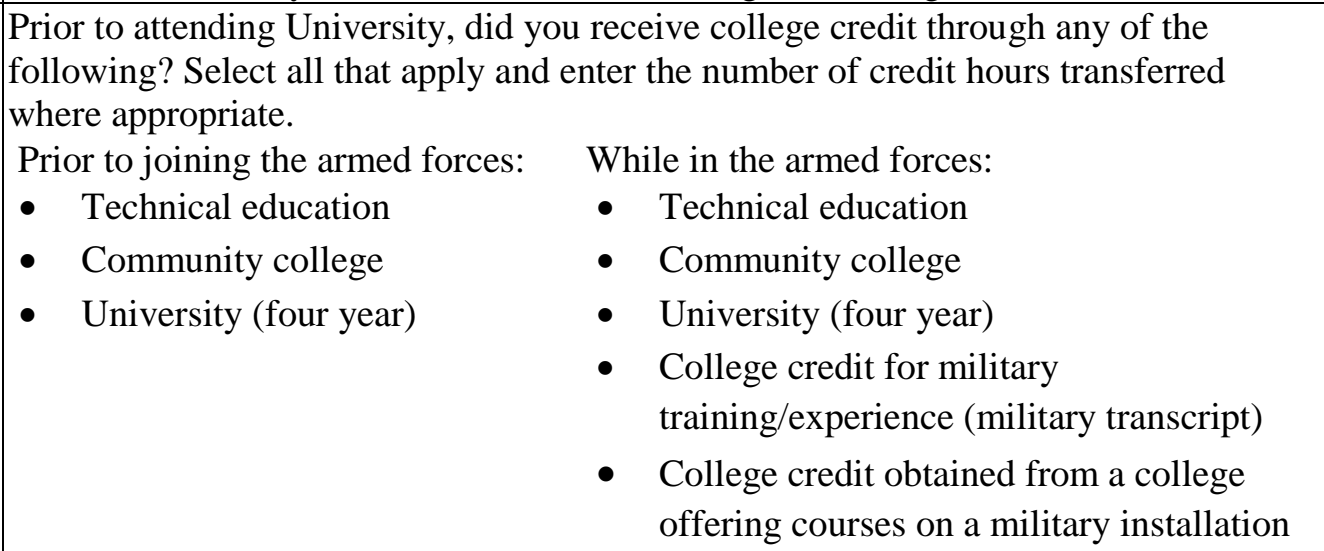 } \\
\hline & \multicolumn{2}{|c|}{$\begin{array}{l}\text { Prior to coming to University, what were your military occupational specialties } \\
\text { (MOS)? Please list all including the title, number, and identify your last MOS. }\end{array}$} \\
\hline & $\begin{array}{l}\text { Years of military service: } \\
\text { (Active Duty) }\end{array}$ & \\
\hline & \multicolumn{2}{|c|}{ How long ago were you discharged from the military? } \\
\hline & \multicolumn{2}{|l|}{ Did you have combat experience? } \\
\hline & \multicolumn{2}{|c|}{ What branch of the military were you a part of? Check all that apply } \\
\hline
\end{tabular}

The pilot survey was approved by the IRB and disseminated to 15 veteran students and 30 first-year students through their university email. The invitation-to-participate emails were sent to each student directly after selecting them using a random generator from the two separate Listservs. Such a mechanism helped to ensure the participants were recruited as intended. In the piloting stage, both the instrument (i.e. the questionnaire itself) and the procedures involved (i.e., the incentive mechanism and administering process) were under testing. The survey was open for two weeks. Only 4 of the 30 first-year students responded in the first week. A follow-up reminder email about the survey was sent to those who had not yet participated through the university learning management system (LMS) as most students use the LMS instead of email to communicate with faculty. In total 9 of the 30 first-years and 10 of the 15 veterans responded to the survey. An additional 30 first-years and 5 veterans were invited to participate to increase the population. Ultimately 15 first-years and 11 veterans responded to the pilot survey. The piloting results will be used to guide any subsequent adjustment needed, before disseminating the full survey this fall. One proposed modification is to disseminate the survey on paper in all first-year department introduction classes due to the minimal response from this cohort.

On the last page of the pilot survey, respondents from both groups are taken to a separate interface and asked if they would be willing to participate in a focus-group interview to provide verbal feedback on the survey items. The separate interface ensured student responses to the survey were separate from any identifiable information, such as their email address. Their 
provision of contact information was considered as consent to participate. A focus-group interview from those who indicated their interest in participating will be then conducted to solicit feedback on the question type, language used, and completeness of the survey. Originally the target number for the focus group was 5 students (3 veteran and 2 non-veteran); however only 8 students indicated interest in participating in the focus group (6 veteran and 2 non-veteran). All were invited to participate as the focus group will be near the end of the semester and finding a time that works for all was difficult. To date, 5 students have confirmed they will attend. Findings from the focus-group discussion will be used to modify the survey. All focus-group interviewees will be compensated for their willingness to participate and time.

Future work

The pilot survey is expected to evaluate the validity of the modified EPRA survey for veteran students. Cronbach's alphas will be performed four times to measure the internal consistency on the scales. Survey items that are intended to measure the first underlying factor, social awareness, will be calculated for a Cronbach's alpha coefficient. The same process will be applied to items measuring the other two underlying factors, professional development and combined social awareness and professional development. The overall consistency of the PSRDM scale will be measured as well. A high value of the alpha coefficient suggests a high reliability. Additionally, considering the sample size and the number of items in the survey in relation to the effectiveness of Cronbach's alphas in measuring the internal consistency of a scale, an exploratory factor analysis will also be conducted. The exploratory factor analysis will evaluate if the survey items load on the three factors (social awareness, professional development, and combined social awareness and professional development) as intended, according to the PSRDM model.

The research team will use the analytical results and feedback from the focus group interview from the pilot phase to further review and revise the survey instrument. The revised survey will be presented to the advisory board for a final review. Any procedural matters learned during the pilot phase will be considered and changes will be made accordingly. The survey will be disseminated to all veteran students and all first-year non-veteran students in the college of engineering in the fall semester when the number of veteran students is traditionally highest. The authors anticipate 100 veteran student responses and 450 first-year student responses based on current enrollment in the college of engineering. Statistical procedures will be applied to analyze the quantitative data from the full survey. The internal consistency of the PSRDM scales (each subscale and the overall scale) will be performed. Multiple regression analyses will be conducted on demographic variables and the PSRDM scale variables. Given that the number of demographic variables can be much higher than the sample size of the veteran student respondents, the Nearest Shrunken Centroid (PAM) will be used for model fitting [21]. T-tests will be conducted to compare the veteran and non-veteran groups on each of the subscale and the overall PSRDM scale. The final phase of the project will be semi-structured formal interviews [22] of veteran students and faculty who have included components related to social responsibility in their classrooms. All interview data will be analyzed using a thematic analysis, which entails an iterated process of coding, categorizing of codes, and generating themes from categories [23]. 
The authors have identified that over 50 percent of veterans who enter the college of engineering at Kansas State University are dismissed or discontinue enrollment. Approximately 34 percent of the discontinued/dismissed students leave after their first semester and another 31 percent leave after their first year. Therefore, the results of the survey will be directly linked to the retention of students following their first semester in fall 2018 and spring 2019. If there is a positive relationship between veteran student retention and social responsibility, the final survey and interview results will be used to propose an intervention.

\section{References}

[1] President's Council of Advisors on Science and Technology, "Engage to excel: Producing one million additional college graduates with degrees in science, technology, engineering, and mathematics," February 2012. [Online]. Available:

https://www.whitehouse.gov/sites/default/files/microsites/ostp/pcast-engage-toexcelfinal_feb.pdf.

[2] National Academies of Sciences, Engineering, and Medicine, "Quality in the Undergraduate Experience: What Is It? How Is It Measured? Who Decides? Summary of a Workshop," The National Academies Press, Washington, D.C., 2016.

[3] National Science Foundation, "2009," Report of the NSF Workshop on Enhancing the Post-9/11 Veterans Educational Benefit, McLean, Virginia, Veterans' education for engineering and science.

[4] B. Cook and Y. Kim, "From soldier to student: Easing the transition of service members on campus," Lumina Foundation for Education, Washington, D.C., 2009.

[5] I. St. Omer, "Engineering veteran pathways," in ASEE Annual Conference \& Exposition, Vancouver, British Columbia, 2011.

[6] A. Radford, Military service members and veterans in higher education: What the new GI bill may mean for postsecondary institutions, New York: American Council on Education, 2009.

[7] A. Rezaei, M. Jawaharlal, J. Caffrey and K. Kim, "Socially Responsible Design Projects in an Undergraduate Engineering Education Program," in ASEE Annual Conference and Exposition, Pittsburgh, Pennsylvania, 2008.

[8] L. Vanasupa, L. Slivovsky and K. Chen, "Global challenges as inspiration: A classroom strategy to foster social responsibility," Science and Engineering Ethics, vol. 12, no. 1, pp. 373-380, 2006. 
[9] K. Meyers and B. Mertz, "A large scale analysis of first-year engineering student essays on engineering interests," in ASEE Annual Conference and Exposition, Washington, D.C., 2011.

[10] J. H. Pryor, K. Eagan, L. P. Blake, S. Hurtado, J. Berdan and M. Case, "The American Freshman: National Norms Fall 2012.," Cooperative Institutional Research Program at the Higher Education, Los Angeles, 2012.

[11] N. A. o. Engineering, "Changing the conversation: Messages for improving public understanding of engineering," National Academies Press, Washington, D.C., 2008.

[12] G. Hein and A. Kemppainen, "First-year engineering students ethical analysis," in ASEE Annual Conference and Exposition, Vancover, 2011.

[13] J. Lo, V. Lohani and J. Mullin, "). Introduction of Contemporary Engineering Ethics Issues in a Freshman Engineering Course," in ASEE Annual Conference and Exposition, New Orleans, 2016.

[14] M. Vigeant, J. Baish, D. Cavanagh, T. DiStefano, X. Meng, P. Vesilind and R. Ziemaian, "Ethics for first-year engineers: The struggle to build a solid foundation," in ASEE Annual Conference and Exposition, Portland, 2005.

[15] N. Canney and A. Bielefeldt, "2014," in ASEE Annual Conference Proceedings, Indianapolis, Social responsibility attitudes of first-year engineering students and the impacts of courses.

[16] N. Canney and A. Bielefeldt, "Validity and reliability evidence of the engineering professional responsibility assessment tool," Journal of Engineering Education, vol. 105, no. 3, pp. 452-477, 2016.

[17] S. Lord, J. Main, C. Brawner, C. Mobley and M. Camacho, "2016," in ASEE Annual Conference and Exposition, New Orleans, Military veteran students' pathways in engineering education (Year 2).

[18] J. Hilpert, G. Stump, J. Husman and W. Kim, "An exploratory factor analysis of the Pittsburgh Freshman Engineering Attitudes Survey," in 38th ASEE/IEEE Frontiers in Education Conference, Saratoga Springs, 2008.

[19] J. Hilpert, G. Stump and J. Husman, "Pittsburgh engineering attitudes scale - revised: evidence for an improved instrument," in Frontiers in Education, Washington, D.C., 2010.

[20] K. Donaldson, H. Chen, G. Toye, M. Clark and D. Sheppard, "Scaling up: Taking the Academic Pathways of People Learning Engineering Survey (APPLES) national," in Frontiers in Education Conference Proceedings, Saratoga Springs, 2008. 
[21] A. Tan, D. Naiman, L. Xu, R. Winslow and D. Geman, "Simple decision rules for classifying human cancers from gene expression proles," Bioinformatics, vol. 21, pp. 38963904, 2005.

[22] I. Seidman, Interviewing as qualitative research: A guide for researchers in education and the social sciences, New York: Teachers College Press, 2006.

[23] V. Braun and V. and Clarke, "Using thematic analysis in psychology," Qualitative Research in Psychology, vol. 3, no. 2, pp. 77-101, 2006. 